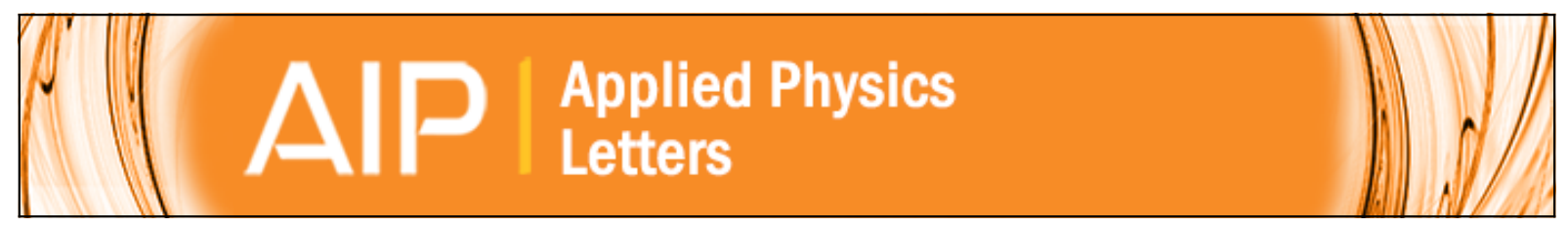

\title{
Investigation of stress-induced (100) platelet formation and surface exfoliation in plasma hydrogenated $\mathbf{S i}$
}

Zengfeng Di, Yongqiang Wang, Michael Nastasi, Francois Rossi, Jung-Kun Lee, Lin Shao, and Phillip E.

Thompson

Citation: Applied Physics Letters 91, 244101 (2007); doi: 10.1063/1.2822414

View online: http://dx.doi.org/10.1063/1.2822414

View Table of Contents: http://scitation.aip.org/content/aip/journal/apl/91/24?ver=pdfcov

Published by the AIP Publishing

\section{Articles you may be interested in}

Influence of hydrogen plasma surface treatment of Si substrate on nickel silicide formation

J. Vac. Sci. Technol. B 24, 1449 (2006); 10.1116/1.2200373

Plasma hydrogenation of strained $\mathrm{Si} / \mathrm{SiGe} / \mathrm{Si}$ heterostructure for layer transfer without ion implantation Appl. Phys. Lett. 87, 091902 (2005); 10.1063/1.2032602

Depth dependence of hydrogenation using electron cyclotron plasma in GaAs-on-Si solar cell structures J. Vac. Sci. Technol. A 17, 453 (1999); 10.1116/1.581605

In situ observation of hydrogenated amorphous silicon surfaces in electron cyclotron resonance hydrogen plasma annealing

J. Appl. Phys. 85, 1172 (1999); 10.1063/1.369242

Amorphous $\{100\}$ platelet formation in (100) Si induced by hydrogen plasma treatment J. Appl. Phys. 81, 74 (1997); 10.1063/1.364098

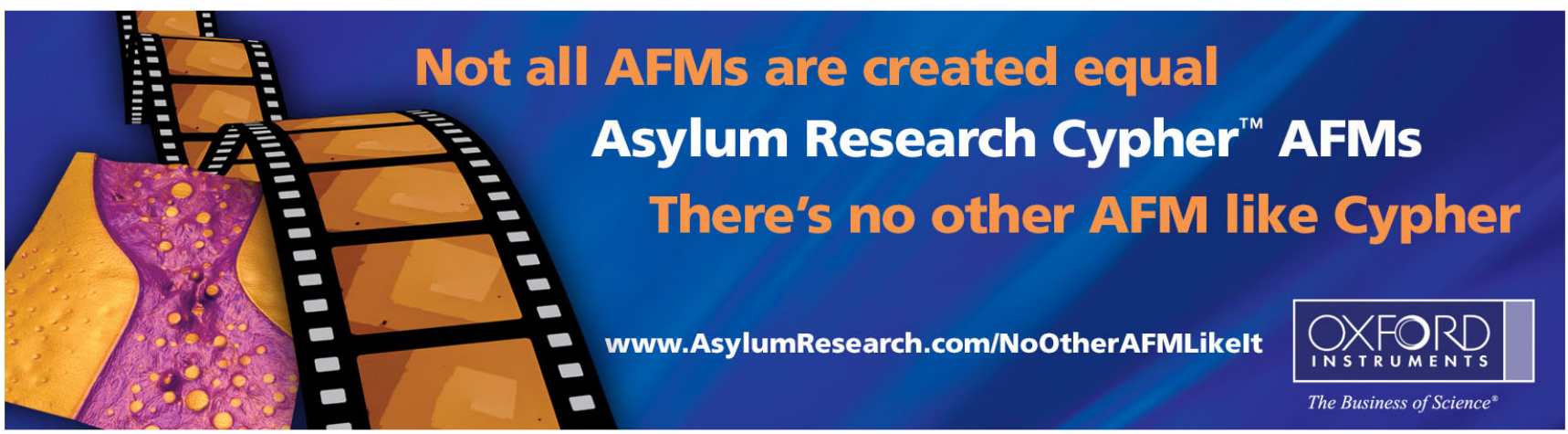




\title{
Investigation of stress-induced (100) platelet formation and surface exfoliation in plasma hydrogenated $\mathrm{Si}$
}

\author{
Zengfeng $\mathrm{Di},{ }^{\mathrm{a})}$ Yongqiang Wang, and Michael Nastasi \\ Los Alamos National Laboratory, Los Alamos, New Mexico 87545, USA \\ Francois Rossi \\ Joint Research Centre, European Commission, 21020 Ispra(Va), Italy \\ Jung-Kun Lee \\ Department of Mechanical Engineering and Materials Science, University of Pittsburgh, Pittsburgh, \\ Pennsylvania 15261, USA \\ Lin Shao \\ Department of Nuclear Engineering, Texas A\&M University, 3133 TAMU, College Station, Texas 77843, \\ USA \\ Phillip E. Thompson \\ Code 6812, Naval Research Laboratory, Washington, D.C. 20375-5347, USA
}

(Received 18 October 2007; accepted 15 November 2007; published online 10 December 2007)

\begin{abstract}
We have studied the mechanisms underlying stress-induced platelet formation during plasma hydrogenation. The stress is purposely introduced by a buried SiGe stained layer in a Si substrate. During plasma hydrogenation, diffusing $\mathrm{H}$ is trapped in the region of the SiGe layer and $\mathrm{H}$ platelets are formed. The platelet orientation is controlled by the in-plane compressive stress, which favors nucleation and growth of platelets in the plane of stress and parallel to the substrate surface, and ultimately leads to controlled fracture along the $\mathrm{SiGe}$ layer. Also, the $\mathrm{Si} / \mathrm{SiGe} / \mathrm{Si}$ structure is found to be more efficient in utilizing $\mathrm{H}$ for platelet formation and growth compared to $\mathrm{H}$ ion implanted Si because there are fewer defects to trap $\mathrm{H}$ (e.g., $V_{n} \mathrm{H}_{m}$ and $I_{n} \mathrm{H}_{m}$ ); therefore, the total $\mathrm{H}$ dose needed for layer exfoliation is greatly reduced. (C) 2007 American Institute of Physics.
\end{abstract}

[DOI: 10.1063/1.2822414]

It is well established that hydrogen implantation in $\mathrm{Si}$ is capable of inducing surface exfoliation. Several mechanisms have been proposed to explain this effect. ${ }^{1-3}$ Weldon et al. ${ }^{1}$ has suggested that the implanted $\mathrm{H}$ produces extended planar defects (platelets), which can trap $\mathrm{H}_{2}$ molecules which build up the internal pressure, cause coalescence, and finally lead to cracking. While the general features of this exfoliation description are commonly accepted, many of the details associated with the various processes leading to platelet nucleation and $\mathrm{H}_{2}$ molecule trapping are still under discussion. For example, it is well-known that platelets only form on $\{111\}$ planes during plasma hydrogenation ${ }^{4}$ and exfoliation is not observed. However, when hydrogen is introduced into Si by ion implantation, platelets are primarily observed to form parallel to the substrate surface ${ }^{5}$ and exfoliation is observed. Recent work by Nastasi et al. ${ }^{6}$ showed that the platelet orientation in both $\mathrm{H}$ ion implanted and plasma hydrogenated $\mathrm{Si}$ could be explained by a Volmer-type nucleation model that accounted for the in-plane compressive stress that is present in the implanted material. ${ }^{7,8}$ Since the stress in ion implanted materials results from radiation defects, it is unclear if the model proposed by Nastasi et al. is also appropriate for situations where an external stress is introduced by other means. In this work, we explore platelet formation and surface exfoliation in plasma hydrogenated single crystalline $\mathrm{Si}$ where a region of plane-stress is introduced by a buried SiGe strain layer.

\footnotetext{
${ }^{\text {a) }}$ Author to whom correspondence should be addressed. Tel.: 505-665-4995.
} FAX: 505-667-8021. Electronic mail: zengfeng@lanl.gov.
A heterostructure composed of a 5-nm-thick epitaxial $\mathrm{Si}_{0.80} \mathrm{Ge}_{0.20}$ layer followed by a 150 -nm-thick crystalline $\mathrm{Si}$ capping layer was grown on a $\langle 100\rangle p$-Si substrate at $650^{\circ} \mathrm{C}$ using molecular beam epitaxy. The samples were subjected to low pressure (1 mTorr) plasma hydrogenation in pure hydrogen at $300{ }^{\circ} \mathrm{C}$, in a distributed electron cyclotron resonance plasma reactor ${ }^{9}$ with a low frequency $(2 \mathrm{kHz})$ bias of approximately $-100 \mathrm{~V}$. Durations of plasma treatments varied from $30 \mathrm{~min}$ to $2 \mathrm{~h}$. Scanning electron microscope (SEM), elastic recoil detection (ERD), and multiple internal reflection infrared spectroscopy (MIR-IR) were used to characterize the samples after hydrogenation.

Figure 1 presents $\mathrm{SEM}$ micrographs of the $\mathrm{Si} / \mathrm{SiGe} / \mathrm{Si}$ samples after hydrogenation. For the shortest treatment $(0.5 \mathrm{~h})$, only tiny blisters $(\sim 30 \mathrm{~nm})$ are detected [Fig. 1(a)]. As the hydrogenation proceeds, these small blisters grow and coalesce. For $1 \mathrm{~h}$ hydrogenation [Fig. 1(b)], large blisters, with a diameter generally of less than $1 \mu \mathrm{m}$ have developed. The $1.5 \mathrm{~h}$ hydrogenated sample [Fig. 1(c)] shows a very high density of blisters with blister diameters between 1 and $1.5 \mu \mathrm{m}$. However, the morphology has visibly changed when the hydrogenation is extended to $2 \mathrm{~h}$ [Fig. 1(d)], where many large exfoliated blisters $(\sim 3.5 \mu \mathrm{m})$ surrounded by a scattering of small blisters can be seen. This local exfoliation is due to the built-up molecular hydrogen which promotes crack propagation along the SiGe layer. ${ }^{10}$

Figure 2(a) shows ERD hydrogen depth profiles from hydrogenated $\mathrm{Si} / \mathrm{SiGe} / \mathrm{Si}$ samples. The amount of integrated hydrogen in each peak is plotted as a function of hydrogenation time in Fig. 2(b). Figure 2(a) shows that even at the lowest hydrogenation exposure time, the $\mathrm{H}$ concentration is 


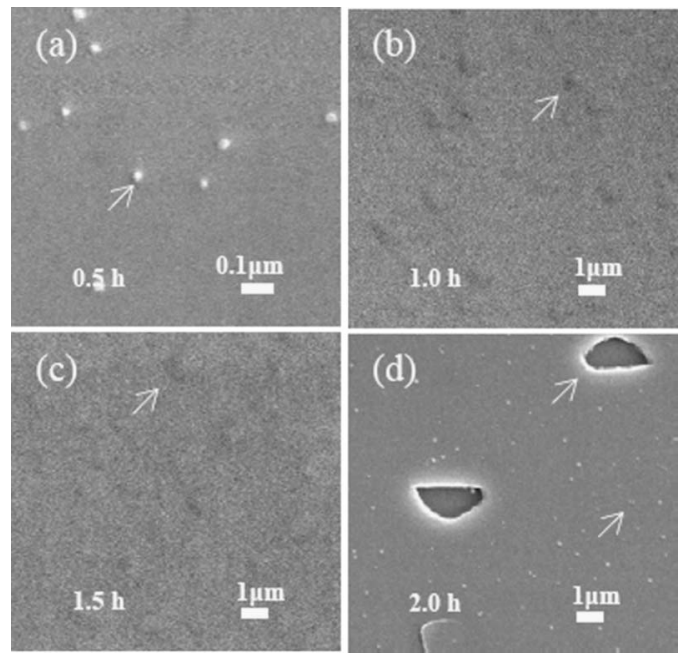

FIG. 1. SEM micrographs from $\mathrm{Si} / \mathrm{SiGe} / \mathrm{Si}$ after plasma hydrogenation for various durations: (a) 0.5 , (b) 1.0 , (c) 1.5 , (d) $2.0 \mathrm{~h}$.

well above the solubility limit in $\mathrm{Si}^{11,12}$ The peak $\mathrm{H}$ concentration increases with hydrogenation time in the range of $0.5-1.5 \mathrm{~h}$. However, the $\mathrm{H}$ concentration drops significantly in the $2 \mathrm{~h}$ hydrogenated sample because of out diffusion of gaseous $\mathrm{H}_{2}$ from exfoliated blisters along with the loss of bonded hydrogen from inner walls of exfoliated blisters.

The hydrogen concentration required for blister formation is about $1 \times 10^{16} \mathrm{~cm}^{-2}$, which is much lower than the fluence of $6 \times 10^{16} \mathrm{~cm}^{-2}$ necessary for commercial ion-cut technology, and comparable with the total fluence of 1.75 $\times 10^{16} \mathrm{~cm}^{-2}$ used in $\mathrm{H} / \mathrm{He}$ coimplantation for layer transfer. ${ }^{13}$ This phenomenon can be explained by the intrinsic difference between ion implantation and plasma hydrogenation. In contrast to ion implantation, the energy of plasma $\mathrm{H}$ ions is not high enough to create significant concentrations of vacancies and interstitials, which in ion implanted samples trap $\mathrm{H}$ in the form of $V_{n} \mathrm{H}_{m}$ or $I_{n} \mathrm{H}_{m}$ defects. ${ }^{14}$ Therefore, for plasma hydrogenation, the lack of irradiation damage means that there are fewer traps competing for $\mathrm{H}$ other than the buried $\mathrm{SiGe}$ strained layer. In this way, $\mathrm{H}$ introduced by plasma hydrogenation can be more efficiently utilized for platelet formation.

The bonding between $\mathrm{H}$ and $\mathrm{Si}$ that results during plasma hydrogenation is investigated using MIR-IR (Fig. 3).

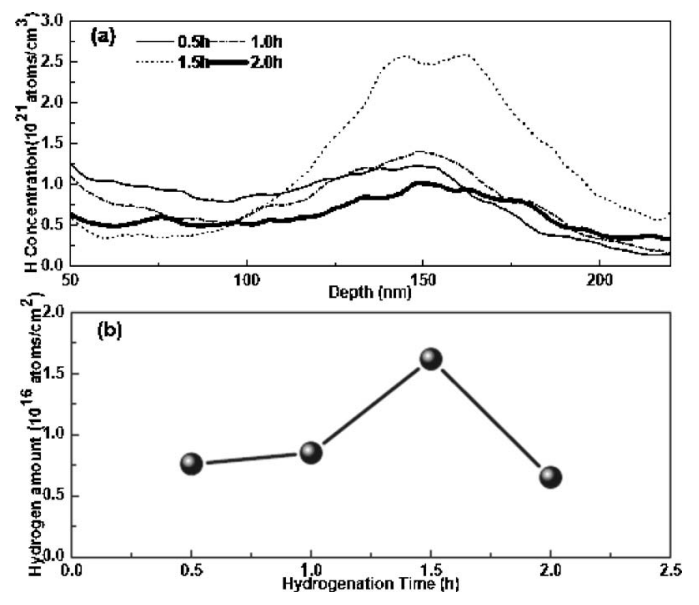

FIG. 2. (a) ERD spectra of hydrogenated $\mathrm{Si} / \mathrm{SiGe} / \mathrm{Si}$ with different durations (b) The total amount of trapping hydrogen as a finction of hydrogenation time.

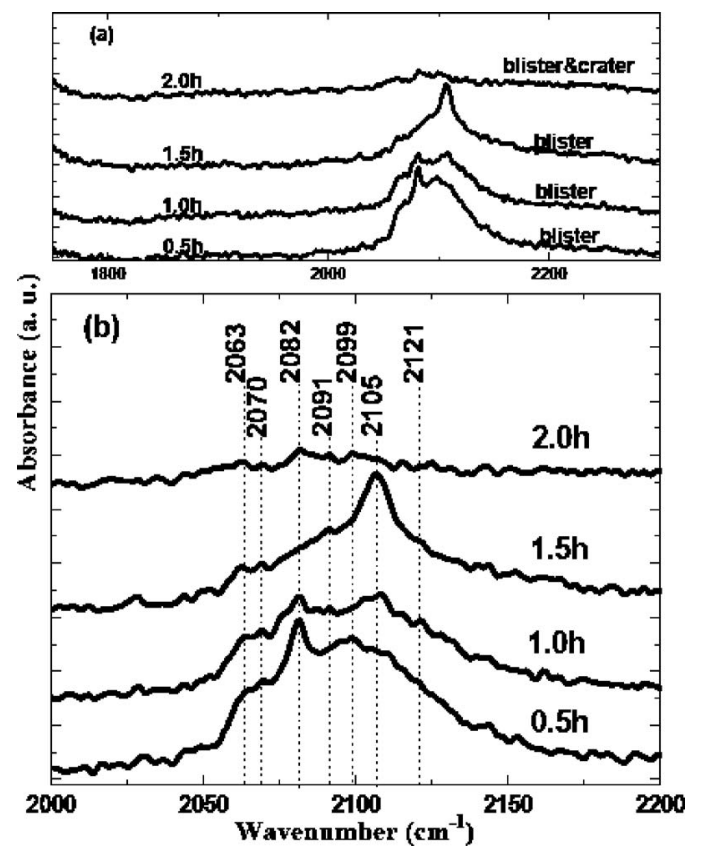

FIG. 3. MIR-IR spectra from hydrogenated $\mathrm{Si} / \mathrm{SiGe} / \mathrm{Si}$ with different hydrogenation durations: (a) 1800-2300 and (b) $2000-2200 \mathrm{~cm}^{-1}$.

Different from the broadband absorption $\left(1800-2300 \mathrm{~cm}^{-1}\right)$ observed in H-implanted samples, ${ }^{1}$ plasma hydrogenated $\mathrm{Si} / \mathrm{SiGe} / \mathrm{Si}$ only shows a narrow absorption region from 2050 to $2150 \mathrm{~cm}^{-1}$ in Fig. 3(a), which is indicative of a lack of $V_{n} \mathrm{H}_{m}$ and $I_{n} \mathrm{H}_{m}$ defects. The intensity of the absorption peaks from the $2 \mathrm{~h}$ hydrogenation sample is significantly reduced due to the loss of bonded hydrogen following blister rupture. All $\mathrm{Si}-\mathrm{H}$ bond stretching modes are marked in Fig. 3 (b). Since (111) platelets form in the near-surface region of hydrogenated $\mathrm{Si}^{4}{ }^{4}$ the modes at 2063,2070 , and $2082 \mathrm{~cm}^{-1}$ are assigned to the unperturbed and perturbed $\mathrm{Si}-\mathrm{H}$ bonds at Si (111) surface. ${ }^{10,15-17}$ The modes at 2091 and $2099 \mathrm{~cm}^{-1}$ are assigned to the asymmetric and symmetric stretching modes of a coupled monohydride species $(\mathrm{SiH})_{2}$ on atomically smooth $\mathrm{Si}(100)$ surfaces, ${ }^{18}$ and the mode at $2121 \mathrm{~cm}^{-1}$ is close to the assignment for the asymmetric dihydride stretching motion on atomically rough $\mathrm{Si}(100)$ surfaces. ${ }^{1,19}$ It should be noted that the stretching mode for $\nu_{\mathrm{s}}(\mathrm{SiH})_{2}$ at $2099 \mathrm{~cm}^{-1}$ shifts to $2105 \mathrm{~cm}^{-1}$ for hydrogenation durations of 1 and $1.5 \mathrm{~h}$; upon further hydrogenation for $2 \mathrm{~h}$, it returns back to $2099 \mathrm{~cm}^{-1}$.

It is well established that the interaction of bonded $\mathrm{H}$ on opposite inner $\mathrm{Si}$ (111) surfaces would lower the $\mathrm{Si}-\mathrm{H}$ frequency, i.e., produce a redshift. ${ }^{20}$ Therefore, the blueshift from 2099 to $2105 \mathrm{~cm}^{-1}$ observed during hydrogenation should not arise from such a dynamic coupling. Weldon et al. ${ }^{20}$ attribute the $2099 \rightarrow 2105 \mathrm{~cm}^{-1}$ blueshift to the steric interaction between $\mathrm{Si}-\mathrm{H}$ bonds and overlying $\mathrm{H}_{2}$ gas. This hypothesis is confirmed by our results which show that the shift from 2099 to $2105 \mathrm{~cm}^{-1}$ is strongly correlated with the $\mathrm{H}$ content in our samples. For the $0.5 \mathrm{~h}$ hydrogenated sample, only a small amount of hydrogen has accumulated at the buried SiGe layer. As hydrogenation increases to 1 and $1.5 \mathrm{~h}$, the hydrogen content, and the probability of $\mathrm{H}_{2}$ molecule formation within platelets, also increases. Gaseous $\mathrm{H}_{2}$ inside large platelets or microbubbles will have steric interactions with $\mathrm{Si}-\mathrm{H}$ bonds on internal (100) surface $^{20}$ and lead to a blueshift from its relaxed state at 2099 to $2105 \mathrm{~cm}^{-1}$, as 
shown in Fig 3. At extended plasma-hydrogenation times, microbubbles explode, gaseous $\mathrm{H}_{2}$ diffuses out though the "popped" blisters, and the mode associated with $\mathrm{Si}-\mathrm{H}$ bonds on internal (100) surfaces returns back to its unperturbed frequency, i.e., $2099 \mathrm{~cm}^{-1}$.

In conventional ion cut, the defects and the corresponding in-plane compressive stress introduced by ion implantation are responsible for hydrogen trapping and platelet nucleation during postimplantation annealing. ${ }^{6}$ For the plasmahydrogenation based layer exfoliation process, exfoliation proceeds from the strained $\mathrm{SiGe}$ layer, which supplies the needed in-plane compressive stress for (100) platelet nucleation and $\mathrm{H}$ trapping. The nucleation of platelets during $\mathrm{Si}$ hydrogenation was discussed by Johnson et al. ${ }^{21}$ where the nucleation of platelets in $\mathrm{Si}$ supersaturated with hydrogen was qualitatively described using a Volmer-type theory. The model proposed by Johnson et al. considered a circular nucleus of radius $R$ forming on a $\{111\}$ plane. The total free energy change upon nucleation of a $\mathrm{H}$ platelet of radius $R$ and thickness $t$ was expressed as

$$
\Delta G(R)=-\pi R^{2} t \Delta G_{v}+2 \pi R \gamma t+2 \pi R c \ln (R) .
$$

In Eq. (1), $\Delta G_{v}$ is the energy difference per unit volume between the supersaturated state and the platelet state. The term $2 \pi R \gamma t$ is the perimeter energy of the platelet nuclei, with $\gamma$ as surface energy. Since $\mathrm{Si}-\mathrm{H}$ bond formation is exothermic relative to the $\mathrm{Si}-\mathrm{Si}$ bond, ${ }^{11} \gamma$ will be negative for platelet formation. The third term, $2 \pi R c \ln (R)$, is the strain energy resulting from formation of nuclei in the Si lattice (with $c$ as a constant), which is modeled as the self-energy of a dislocation loop of radius $R$. For $\mathrm{H}$ platelet nucleation in $\mathrm{Si}$, the first two terms in Eq. (1) supply the driving force for nucleation, while the strain energy is a barrier term.

Equation (1) is sufficient to describe the nucleation process in the absence of applied stresses, such as at the surface of our hydrogenated sample. However, in the region of the SiGe strain layer, a state of biaxial compressive stress exists that adds an additional term to Eq. (1) of the form ${ }^{22}$

$$
-\sigma_{n n} \mathrm{~b}_{n} \pi R^{2} \text {, }
$$

where $\mathrm{b}_{n}$ is the Burgers vector of the platelet loop, $\sigma_{n n}$ is the externally applied stress (i.e., in-plane residual stress in our case) acting on the platelet, and $\sigma_{n n} \mathrm{~b}_{n}$ is a tensor product. Equation (2) will be zero when the stress and Burgers vector are orthogonal, indicating that there will be no effect from Eq. (2) on platelets nucleating with their surface parallel to the $\mathrm{Si} / \mathrm{SiGe}$ interface [i.e., (100) platelets]. However, for any other platelet orientations, Eq. (2) will be positive. Therefore, there is an energetic barrier to any platelet not nucleating in the plane of stress. This explains why (111) platelets are observed in the stress-free surface region of our hydrogenated sample but not near the SiGe strain layer. ${ }^{17}$ This same reasoning also explains why absorption modes from (100) platelets are observed in our samples with a SiGe strain layer but not in low temperature hydrogenated bulk $\mathrm{Si}^{23}$

As supersaturated $\mathrm{H}$ is consumed in the nucleation and growth of platelets, the local concentration of free $\mathrm{H}$ diminishes and creates a local $\mathrm{H}$ sink. The further trapping of $\mathrm{H}$ allows the platelet to grow as well as accumulate $\mathrm{H}_{2}$. As shown by Freund, ${ }^{24}$ the final size of a platelet is proportional to the square root of the amount of gaseous $\mathrm{H}_{2}$ molecules in the platelet. The accumulation of $\mathrm{H}_{2}$ pressurizes the platelets, which drives them to grow into microbubbles and ultimately to exploded. Consequently, the highly pressurized $\mathrm{H}_{2}$ in the microbubbles perturbs the $\mathrm{Si}-\mathrm{H}$ bonds attached to the platelet surfaces, consistent with the observed blueshift from 2099 to $2105 \mathrm{~cm}^{-1}$ in the MIR-IR spectra.

In summary, the buried SiGe layer acts as a $\mathrm{H}$ trapping center during hydrogenation and $\mathrm{H}$ platelets are formed at the depth of SiGe layer. The platelet orientation is strongly dependent on the in-plane compressive stress introduced by the SiGe layer, which determines the cleavage location (at the depth of the stain layer) and cleavage orientation (in the plane of stress and parallel to the substrate surface).

This work is supported by the Department of Energy, Office of Basic Energy Science and by the Office of Naval Research.

${ }^{1}$ M. K. Weldon, V. E. Marsico, Y. J. Chabal, A. Agarwal, D. J. Eaglesham, J. Sapjeta, W. L. Brown, D. C. Jacobson, Y. Caudano, S. B. Christman, and E. E. Chaban, J. Vac. Sci. Technol. B 15, 1065 (1997).

${ }^{2}$ F. A. Reboredo, M. Ferconi, and S. T. Pantelides, Phys. Rev. Lett. 82, 4870 (1999).

${ }^{3}$ J. Grisolia, G. B. Assayag, and A. Claverie, Appl. Phys. Lett. 76, 852 (2000).

${ }^{4}$ N. H. Nickel, G. B. Anderson, N. M. Johnson, and J. Walker, Phys. Rev. B 62, 8012 (2000).

${ }^{5}$ T. Höchbauer, A. Misra, M. Nastasi, and J. W. Mayer, J. Appl. Phys. 89, 5980 (2001).

${ }^{6}$ M. Nastasi, T. Höchbauer, J.-K. Lee, A. Misra, J. P. Hirth, M. Ridgway, and T. Lafford, Appl. Phys. Lett. 86, 154102 (2005).

${ }^{7}$ Y. Zheng, S. S. Lau, T. Höchbauer, A. Misra, R. Verda, X.-M. He, M. Nastasi, and J. W. Mayer, J. Appl. Phys. 89, 2972 (2001).

${ }^{8}$ T. Höchbauer, A. Misra, M. Nastasi, and J. W. Mayer, J. Appl. Phys. 92, 2335 (2002).

${ }^{9}$ T. Lagarde, J. Pelletier, and Y. Arnal, J. Phys. IV 8, 121 (1998).

${ }^{10}$ L. Shao, Y. Lin, J. K. Lee, Q. X. Jia, Y. Wang, M. Nastasi, P. E. Thompson, N. David Theodore, P. K. Chu, T. L. Alford, J. W. Mayer, P. Chen, and S. S. Lau, Appl. Phys. Lett. 87, 091902 (2005).

${ }^{11}$ C. G. Van de Walle, Phys. Rev. B 49, 4579 (1994).

${ }^{12}$ R. C. Newman, M. J. Binns, S. A. McQuaid, and E. C. Lightowlers, Solid State Phenom. 32-33, 155 (1993)

${ }^{13}$ A. Agarwal, T. E. Haynes, V. C. Venezia, O. W. Holland, and D. J. Eaglesham, Appl. Phys. Lett. 72, 1086 (1998).

${ }^{14}$ Y. Ma, R. Job, W. Düngen, Y. L. Huang, W. R. Fahrner, M. F. Beaufort, S. Rousselet, and J. T. Horstmann, Appl. Phys. Lett. 86, 252109 (2005).

${ }^{15}$ M. K. Weldon, Y. J. Chabal, D. R. Hamann, S. B. Christman, E. E. Chaban, and L. C. Feldman, J. Vac. Sci. Technol. B 14, 3095 (1996).

${ }^{16}$ Y. Ma, Y. L. Huang, W. Düngen, R. Job, and W. R. Fahrner, Phys. Rev. B 72, 085321 (2005).

${ }^{17}$ L. Shao, Y. Lin, J. G. Swadener, J. K. Lee, Q. X. Jia, Y. Q. Wang, M. Nastasi, P. E. Thompson, N. Dabid Theodore, T. L. Alford, J. W. Mayer, P. Chen, and S. S. Lau, Appl. Phys. Lett. 88, 021901 (2006).

${ }^{18}$ M. K. Weldon, B. B. Stefanov, K. Raghavachari, and Y. J. Chabal, Phys. Rev. Lett. 79, 2851 (1997).

${ }^{19}$ Y. J. Chabal, M. K. Weldon, Y. Caudano, B. B. Stefanov, and K. Raghavachari, Physica B 273-274, 152 (1999).

${ }^{20}$ M. K. Weldon, V. E. Marsico, Y. J. Chabal, D. R. Hamann, S. B. Christman, and E. E. Chaban, Surf. Sci. 368, 163 (1996).

${ }^{21}$ N. M. Johnson, C. Herring, C. Doland, J. Walker, G. Anderson, and F. Ponce, Mater. Sci. Forum 83, 33 (1992).

${ }^{22}$ The elastic field of the platelet is well described as that of a prismatic dislocation loop growing in the presence of a Peach-Koehler force $\sigma b$, where $\sigma$ is the applied stress and $b$ is the Burgers vector of the dislocation.

${ }^{23}$ R. Job, A. G. Ulyashin, W. R. Fahrner, M.-F. Beaufort, and J.-F. Barbot, Eur. Phys. J.: Appl. Phys. 23, 25 (2003).

${ }^{24}$ L. B. Freund, Appl. Phys. Lett. 70, 3519 (1997). 